\title{
Chemical processes effect on ambient air quality: modelling and primary/secondary pollutants monitoring study
}

\author{
M. S. Al-Salem ${ }^{1}$, A. Al-Haddad ${ }^{2}$ \& A. Rehman Khan $^{3}$ \\ ${ }^{1}$ Petrochemical Processes Program Element, Petroleum Research and \\ Studies Centre, Kuwait Institute for Scientific Research, Kuwait \\ ${ }^{2}$ Chemical Engineering Department, College of Engineering and \\ Petroleum, Kuwait University, Kuwait \\ ${ }^{3}$ Environment and Urban Development Division, \\ Coastal and Air Pollution Department, \\ Kuwait Institute for Scientific Research, Kuwait
}

\begin{abstract}
The aim of this paper is to show the monitoring results of airborne pollutants around an urban area surrounded with a number of industrial facilities in the state of Kuwait. Data collected (2004-2005) in two different spans included primary and secondary ambient pollutants as well as major metrological conditions. The adsorption effect of $\mathrm{PM}_{10}$ on methane gas and other atmospheric chemicals recorded was investigated. A series of concentration and wind roses were constructed to study the prevailing wind and dispersion manner of the airborne chemicals from the different sources. Seasonal analysis was carried out with respect to ground and ambient methane levels from the upstream and downstream neighbouring facilities. A discussion on future strategies for the reduction of the different emitted pollutants from the industrial sites is given.

Keywords: primary pollutants, metrological conditions, downstream, airborne, methane.
\end{abstract}

\section{Introduction}

Downstream industry in the state of Kuwait is expanding due to a number of reasons mainly the increase of the local demand on certain crude oil cuts. 
Three refineries process over 1 million BPD are located on the coast line of the urban estate of Kuwait. Applying point source graphing for source determination is paramount to estimate the emissions of pollutants to compute ground level concentrations using dispersion models. The computed model results were synchronized to real time measurements certifying the sources and their respective emission rates. A new approach in estimating elevated source strengths was developed in Pelliccioni and Tirbassi research [1]. The following equation was adapted from the original Gaussian (Normal Distribution) model equation and simulated in a cross wind manner:

$$
C(x, y, 0)=C_{y}\left[\exp -\left(y^{2} / 2 \sigma y^{2}\right)\right] /(2 \Pi \sigma y)
$$

where; $C(x, y, 0)$ is the pollutant concentration, $x$ is the downwind distance, $y$ the crosswind distance and $\sigma y$ the crosswind spread of the plume

The methodology used was able to improve the error average between the calculated values and the measured ones from 10 different stacks and open tanks. The error decreased from 0.992 to 0.009 . In a previous study by Al-Salem et al [2], a series of concentration roses were plotted in a blowing from fashion to monitor the dominate wind and air pollutants on a residential area. The research concluded that the residential area also had excess ambient levels of NOx, CO, $\mathrm{H}_{2} \mathrm{~S}$, and ammonia. El-Fadel et al. [3] determined the effects of industrial emissions and the threat a gas like methane can pose to global climate change in the previous decade. An inventory revealed that the industrial sector contributes about $29 \%$ to the total greenhouse emissions. They proposed the following correlation to estimate the green house effects of methane gas:

$$
Q_{i}=A \times q_{i}
$$

where; $Q_{i}$ is the total process emission of gas $i$ in giga grams , $A$ is the production in tons for industrial processes or in $T j$ for the energy sector and $q_{i}$ is the emission factor for gas $i$ in giga grams/ton

Health risk assessment using passive samples were analyzed and an annual population risk was calculated due to industrial emissions by Al-Salem and Bouhamrah [4]. Ambient levels of BTEX were studied and an industrial are was divided into three sites to estimate the health effects of PAHs and VOCs.

\section{Data collection, materials and software}

Locating a receptor point is an essential step in data collection when it comes to air pollution source allocation. The residential area monitored was in the north northwest of the largest in capacity oil refinery in Kuwait (Mina Al-Ahamdi refinery) and the downwind direction of the greater Burgan oil filed. The receptor point chosen was the main health center of the area (Figure 1.). The data collected in the present work included all the primary metrological conditions data and ambient concentrations of pollutants that included: $\mathrm{NOx}, \mathrm{SO}_{2}$, benzene $\left(\mathrm{C}_{6} \mathrm{H}_{6}\right)$, methane $\left(\mathrm{CH}_{4}\right)$ and $\mathrm{CO}$. Metrological data included wind speed, wind 
direction, percentage relative humidity and ambient temperature. Data were collected in two fashions, original five minute interval data and hourly mean. The main instrument used in the data collection was a fixed five meter probe (Group TEK. Model) located on the main health center of the area. EnviDAS software was used to record the pollutants and transform it into EXCEL spreadsheets. Collected data were plotted as concentration roses (CR) using $15^{\circ}$ spans of the unfiltered data points. CRs gave an initial feel for the prevailing wind directions and the major sources of the primary pollutants in the area.

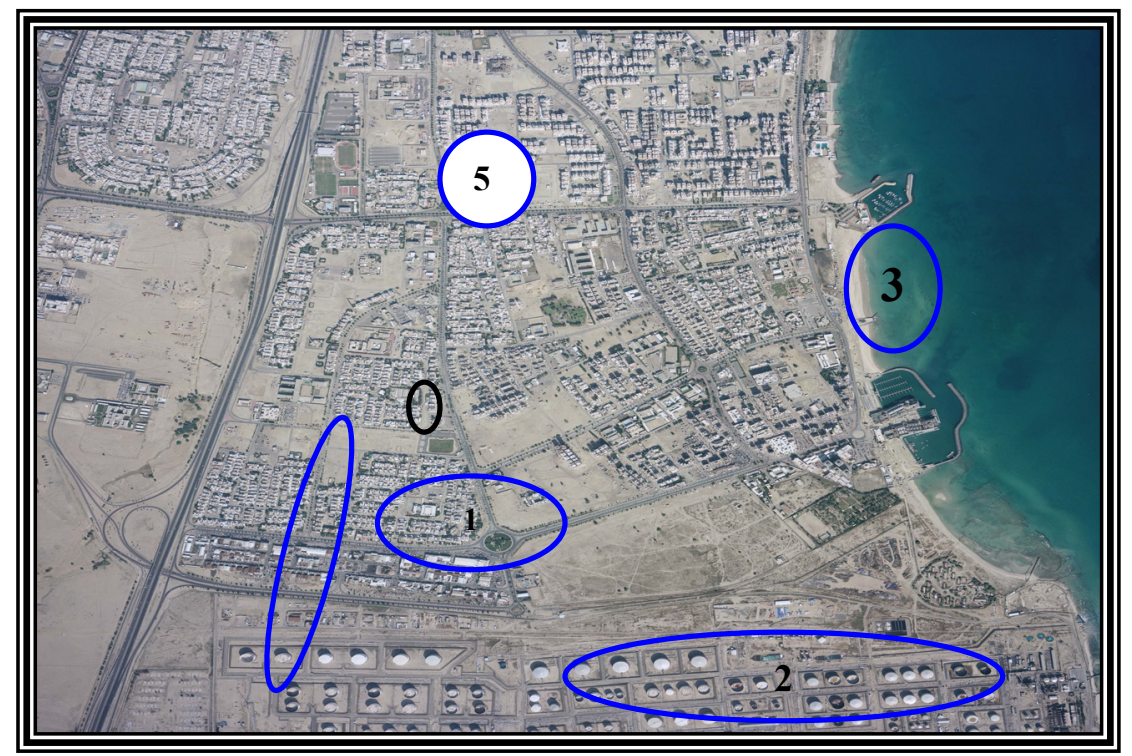

Figure 1: $\quad$ Satellite image of monitored residential area showing the location of the probes used to collect the data (Black circle), and major air pollution sources in the area (blue circles): point 1 shows the main Fahaheel housing area, point 2 shows the MAA refinary gas storage tanks and tank farms, point 3 is the location of the downtown area, point 4 is the Fahaheel main highway and point 5 is Fahaheel sports club.

Figure 2 is an unfiltered concentration rose plotted for the year January 2005, $\mathrm{SO}_{2}$ was blowing directly from the refinery side. The other industries contribute to the background concentrations of a variety of airborne pollutants. The second dominate source can be detected from the north-north west side which corresponds to Burgan oil filed down winds. Figure 5 shows an unfiltered concentration rose for July 2004. The main source can be determined from the rose as a southern one between $180^{\circ}$ to $255^{\circ}$. It can be noticed that methane values are in peaks from the north direction as well, which indicate from the shape of the rose that a number of sources do exist around the area. 


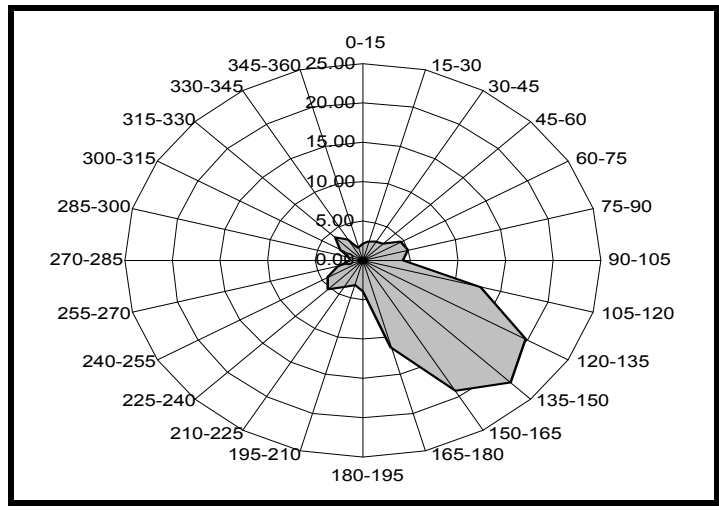

Figure 2: Unfiltered concentration rose for the month of January 2005, $\mathrm{SO}_{2}$ gas.

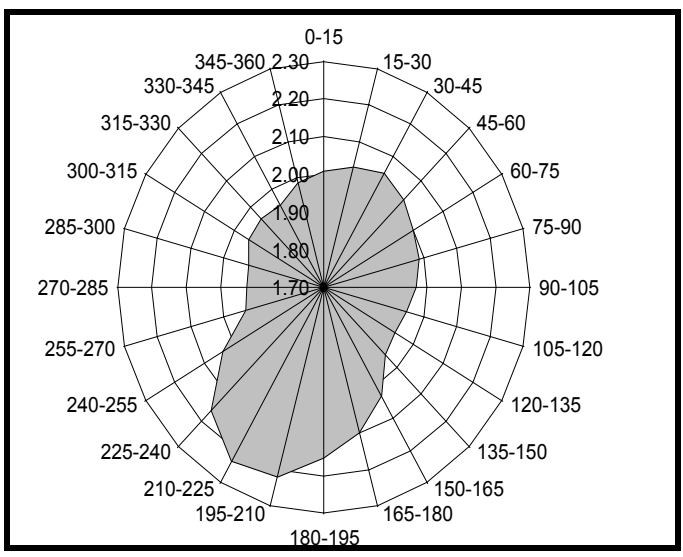

Figure 3: Unfiltered concentration rose for the month of July 2004, methane gas.

Ellipsoid shape CRs were noticed to be in summer periods (July and August) in the area. The prevailing winds in the summer period and their high velocities dispense the gas more than the cooler times. The dot shape $\mathrm{CR}$ can be noticed in periods of temperatures below $30^{\circ} \mathrm{C}$ (Figure 4.), were the ellipsoid like shape can be noticed in a climate of temperatures around $38^{\circ} \mathrm{C}$ and exceeding. The original data collected was filtered using the OX relation of ambient accumulative concentration levels $[5,6]$. Filtered data came to $3 \%$ of the collected original data.

The series of CRs constructed concluded that the main methane source that highly contributes to the receptor point is blowing directly from the MAA refinery side many sources can be noticed but none are as highly noticeable as the MAA refinery side one, were methane gas (in all the 19 months data) was 
blowing from that side in continues manner with increasing rates. The refinery side occupies the southeastern and western border of the area, making it impossible not to notice the effect and emission rates of methane gas in the monitoring station.

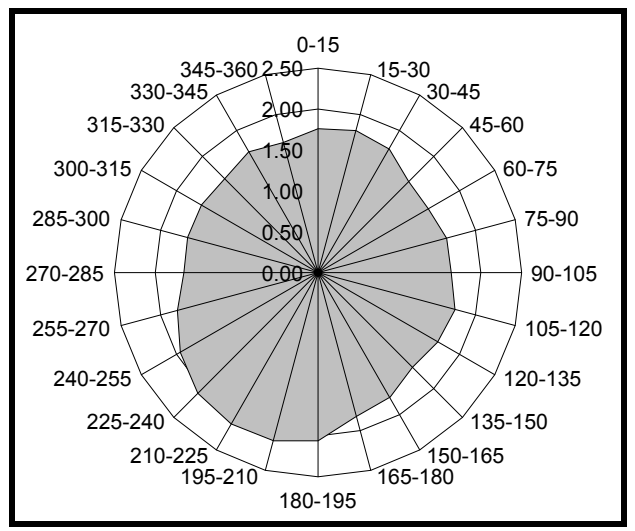

Figure 4: Unfiltered concentration rose for September 2004, methane gas.

\section{Modelling step}

Filtered data points were thoroughly investigated to model the area under investigation. An adaptation of the Guassian (Normal Distrubution) model was used in this study to estimate the major source of methane emmision. Chemical and physical nature of effluents are considered to be very important in terms of choosing the Gaussian model. Estimating a point's concentration for an elevated source can be done using the traditional Gaussian (Normal Distribution) model equation known. Minor assumptions are made to fit the model to our case. Equation (3) expresses the traditional Gaussian equation used to estimate the concentrations in an elevated source level, adding the reflection contribution term. Researchers estimate the reflection distance to be double the stack or source height.

$$
\begin{gathered}
C(x, y, z)=\left(Q /\left(2 \Pi u \sigma_{z} \sigma_{y}\right)\right)\left[\exp -\left(y^{2} /\left(2 \sigma_{y}^{2}\right)\right)\right]\left[\exp \left(-(z-H)^{2} /\left(2 \sigma_{z}^{2}\right)\right)+\right. \\
\left.\exp \left(-(z+H)^{2} /\left(2 \sigma_{z}^{2}\right)\right)\right]
\end{gathered}
$$

where, $C(x, y, z)$ is the concentration of a certain airborne pollutant with respect to the three coordinates, $Q$ is the emission strength of the source in (mass/time), $H$ is the source effective height estimated as $H=h+\Delta h$, where $h$ is the true height of the source and $\Delta h$ is the plume rise all in meters, $u$ is the wind speed in $\mathrm{m} / \mathrm{s}), z$ is the receptor point elevation in meters, $x, y$ and $z$ are the coordinates 
from the imaginary axis drawn with respect to the wind direction, $\sigma_{y}$ and $\sigma_{z}$ are the dispersion coefficients with units of meters or Kilometers. The calculations in this study are based on the stability class $\mathbf{C}$ and its conditions since it is the most reported one in the state of Kuwait [7]. The two dispersion coefficients were either estimated in graphical means or better yet calculated from fitted linear correlations. Both dispersion coefficients were evaluated from Wark [8].

The methane concentration and conditions used to model the dispersion manner for the point source followed Table 1 in terms of the points used to calculate the emissions of the MAA refinery. The month of July 2004 was chosen since methane recorded high activities along the month. The value in the table corresponded to the Southeast direction $\left(169^{\circ}\right.$-Refinery side) with respect to the maximum concentration of methane at that time. A few assumptions were made regarding the modeling of our point source. First, the downwind direction (Southeast) was considered to be the only wind at the time of measuring, thus corresponding to the imaginary axis drawn. The second assumption was considering the source in the refinery (Tank farm/South side) half full at all times; giving an elevation of $10 \mathrm{~m}$. This means no effective stack height is calculated, taking $H$ equals to $10 \mathrm{~m}$ at all times. This is very important to be careful when choosing the Gaussian model. The downwind direction was chosen as the imaginary axis. Figure 4 show the imaginary axis scale with respect to the point source and the receptor point.

Table 1: Recorded methane conditions used in estimating the emissions of the refinery as a point source.

\begin{tabular}{|c|c|c|c|c|c|c|c|c|}
\hline Day & Date & Week & $\begin{array}{c}\text { Peak } \\
\text { time }\end{array}$ & $\begin{array}{c}\text { Peak } \\
\text { Value } \\
(\mathrm{ppm})\end{array}$ & $\begin{array}{c}\text { Wind } \\
\text { direction } \\
(\mathrm{deg})\end{array}$ & $\begin{array}{c}\text { Temp. } \\
\left({ }^{\circ} \mathrm{C}\right)\end{array}$ & $\begin{array}{c}\text { Humidity } \\
\%\end{array}$ & $\begin{array}{c}\mathrm{u} \\
(\mathrm{m} / \mathrm{s})\end{array}$ \\
\hline Monday & $19^{\text {th }}$ & 3 & $\begin{array}{c}8: 00 \\
\mathrm{pm}\end{array}$ & 3.33 & 169 & 40.2 & 36 & 4 \\
\hline
\end{tabular}

The distance between the receptor point and the source in the refinery was $14.5 \mathrm{~cm}$ on the paper scale, which corresponds to $2230.5 \mathrm{~m}(2.2 \mathrm{~km})$ in real distance with respect to the scale of the image. The concentration of methane was taken as $3.33 \mathrm{ppm}$ which converts to $2.174 \mathrm{mg} / \mathrm{m}^{3}$. The dispersion coefficients $\mathrm{y}$ and $\mathrm{z}$ were calculated to be respectively $29.858 \mathrm{~km}$ and $127.323 \mathrm{~km}$. The $\mathrm{Q}$ value was calculated to be $1.04 \mathrm{gm} / \mathrm{s}$. This calculated number gave the value of methane being emitted from the point source to Fahaheel area. The objective was to calculate the rate of methane being emitted from the whole refinery side. The refinery area is reported to be $10,533,400 \mathrm{~m}^{2}$, and by dividing by that number the rate of methane being emitted is found to be equal to $10 \mathrm{gm} /\left(\mathrm{m}^{2} . \mathrm{s}\right)$. Taking a plus or minus one percent for unaccounted emissions or conditions. Of course the main methane sources in MAA refinery were mentioned once before as tank farms, LPG units, and gas gathering centers. In addition to, cracking units and the gas pipe lines. 


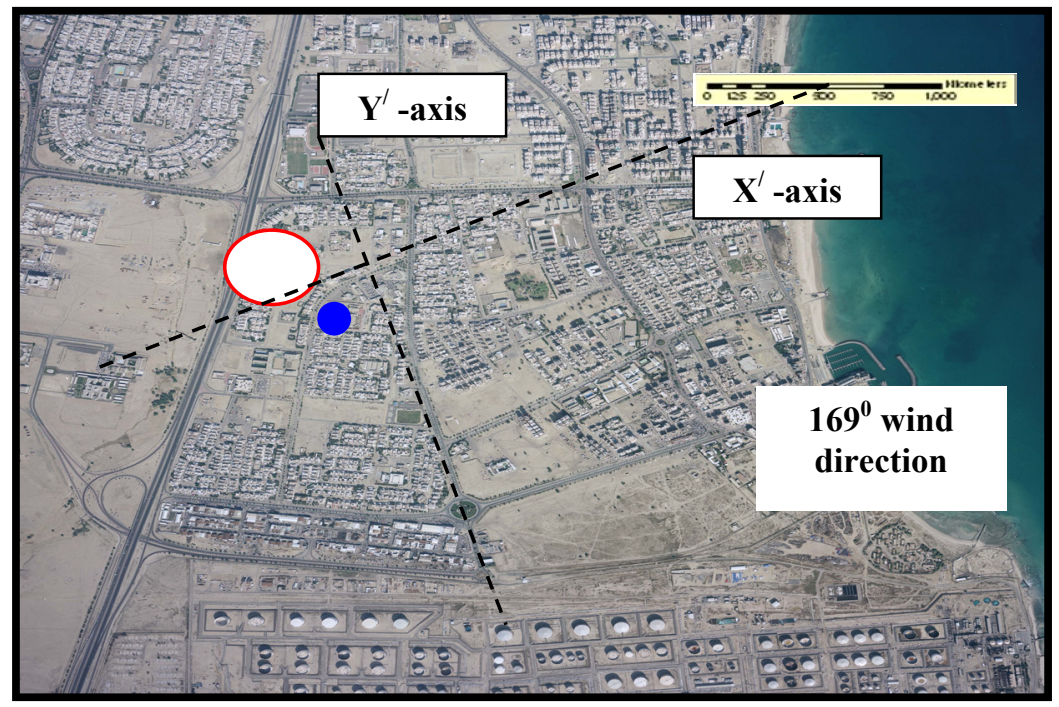

Figure 4: Imaginary axis lines for point source modeling, the corresponding coordinates were: $x=14.5 \mathrm{~cm}$ and $y=2.1 \mathrm{~cm}$. The blue dot represents the source at the refinery (Tank farm) and the red circle represents the receptor point.

Table 2: $\quad$ Concentration profile values obtained from Equation (6).

\begin{tabular}{|c|c|c|c|c|}
\hline $\begin{array}{c}x \text { imaginary } \\
(\mathrm{cm})\end{array}$ & $x$ real $(m)$ & $\sigma_{\mathrm{y}}(\mathrm{km})$ & $\sigma_{\mathrm{z}}(\mathrm{km})$ & $\mathrm{C}\left(\mathrm{mg} / \mathrm{m}^{3}\right)$ \\
\hline 14.5 & 2230.769 & 29.8 & 127.36 & 2.03 \\
\hline 14 & 2153.846 & 28.75 & 123.3 & 2.169 \\
\hline 13 & 1999.99 & 26.53 & 115.25 & 2.48 \\
\hline 12 & 1846.153 & 24.32 & 107.22 & 2.87 \\
\hline 11 & 1692.307 & 22.12 & 98.92 & 3.34 \\
\hline 10 & 1538.46 & 19.98 & 90.66 & 3.93 \\
\hline 9 & 1384.46 & 17.79 & 82.33 & 4.68 \\
\hline 8 & 1230.76 & 15.66 & 73.92 & 5.26 \\
\hline 5 & 769.23 & 9.4 & 48.09 & 9.5 \\
\hline 4 & 615 & 7.37 & 39.21 & 9.96 \\
\hline 3 & 307.692 & 5.3 & 30.1 & 7.2 \\
\hline 2.5 & 384.61 & 4.4 & 25.5 & 4.14 \\
\hline 2 & 307.692 & 3.43 & 20.8 & 1.1 \\
\hline
\end{tabular}

\section{Results and discussion}

The Gaussian model dealt with the strength of the primary source rather than its contribution. After calculating the strength of the source, the concentration profile was developed in order to asses the touch down point in the investigated 
area. Equation 4 is the obtained equation (Concentration profile) that resulted from plugging the obtained source strength $\mathrm{Q}$ in the Gaussian equation. Table 2 show the calculated concentrations from the formulation got from the model.

$$
\begin{gathered}
C(x, y, z)=\left(1.04 \mathrm{gm} / \mathrm{s} /\left(2 \Pi(4 \mathrm{~m} / \mathrm{s}) \sigma_{z} \sigma_{y}\right)\right)\left[\exp -\left(y^{2} /\left(2 \sigma_{y}{ }^{2}\right)\right)\right] \\
\times\left[\exp \left(-(z H)^{2} /\left(2 \sigma_{z}^{2}\right)\right)+\exp \left((z+H)^{2} /\left(2 \sigma_{z}^{2}\right)\right)\right]
\end{gathered}
$$

The values tabulated above are the basis of the Gaussian (Normal Distribution) graph that will be discussed in the upcoming section. The modification came in excluding the effective height and using the half full height at the tank farm. The refinery side gave a $2 \mathrm{ngm} / \mathrm{s} . \mathrm{m}^{2} \mathrm{NO}_{2}$ emission rate or strength (MAA refinery total area $=10533400 \mathrm{~m}^{2}$ ), taking in perspective the total area of the refinery. Methane is known to be one of many existing hydrocarbons in the atmosphere were it can disperse and be absorbed like any other gas. Over the course of this study, it was noticed that methane had an opposite trend with the dust levels in the ambient. Dusty seasons are known in Kuwait to be summer and beginning of the autumn. Dust means in micrograms $/ \mathrm{m}^{3}$ and methane mean values in ppm are tabulated in Table 3.

Table 3: $\quad$ Methane and dust mean averages.

\begin{tabular}{|c|c|c|}
\hline MONTH & METHANE MEAN $(\mathrm{ppm})$ & DUST MEAN $\left(\mathrm{ug} / \mathrm{m}^{3}\right)$ \\
\hline APRIL04 & 2.06 & 120.65 \\
\hline MAY04 & 2.05 & 446.29 \\
\hline JUNE04 & 1.97 & 177.82 \\
\hline JULY04 & 2.02 & 167.77 \\
\hline AUGUST04 & 1.92 & 132.00 \\
\hline SEP04 & 1.74 & 167.00 \\
\hline NOV04 & 2.05 & 264.00 \\
\hline DEC04 & 1.97 & 378 \\
\hline JAN05 & 1.81 & 143 \\
\hline FEB05 & 1.92 & 199 \\
\hline
\end{tabular}

It is clear that dust levels based on monthly means reached in the filtered data points up to 446 micrograms $/ \mathrm{m}^{3}$ in the beginning of the summer season of year 2004. Wind speed is in a direct relation with the dust levels in the ambient. Summer seasons are always associated with high wind velocities. Figure 5 is a graph constructed to plot dust levels with methane ones against time periods in monthly durations. It is noticeable from the figure that dust levels increase in hot periods in Kuwait and methane levels are minimum with high dust levels. This effect is known as "Dust adsorption" of methane in the ambient [11]. Methane levels vary from month to month. The cooler periods help methane settle in the atmosphere and suspend for a longer period in the lower layer of the ambient air. Severe metrological conditions like high wind velocities help dispense methane gas and make it scarce in the surrounding outdoors. July is always a good representative of summer periods in Kuwait. Figure 5 is the stock graph of the month of July 2004, with minimum, maximum and mean values of every day of the month present on it. Almost all of the methane mean values correspond to a lower mean of dust recorded. In plotting the normal distribution 
concentration profile that was developed (Table 2) one can develop the regular dome shape of the normal distribution model. Figure 6 is the one developed for this purpose were the touch down point is circled and found out to be at $x$ imaginary equals to $10.02 \mathrm{~cm}$ which corresponds to 1541 meters from the MAA refinery which is exactly on the main housing area of the urban estate studied.

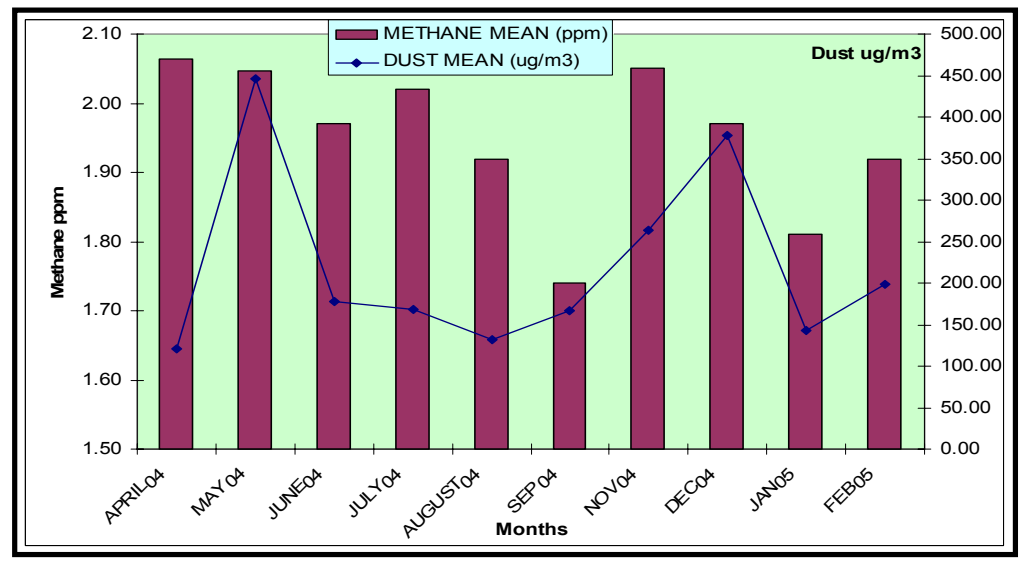

Figure 5: Dust and methane levels plotted against months.

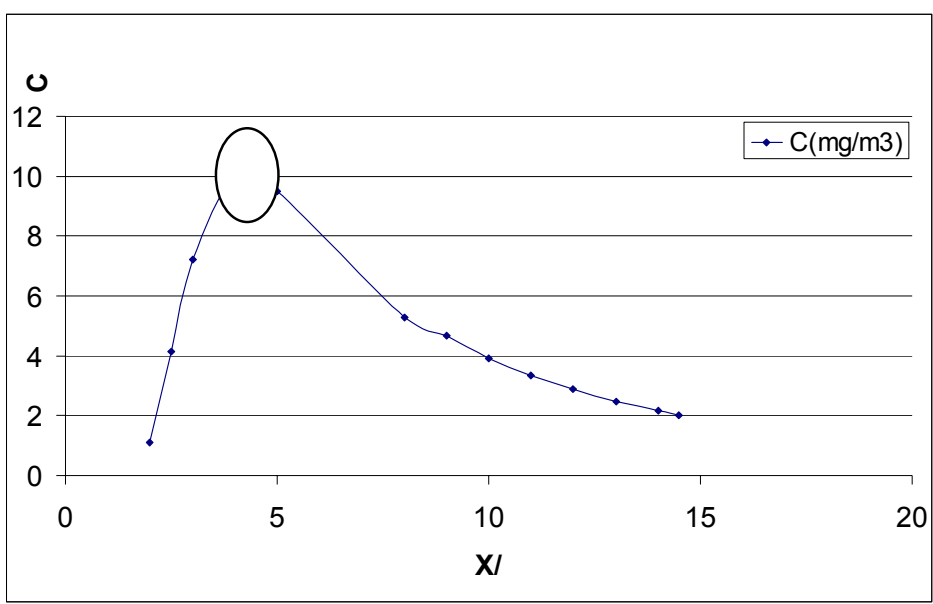

Figure 6: Normal distribution of methane gas over studied area.

\section{Conclusion}

With the use of the Gaussian model, a residential area was modeled and the strength of the main source of methane was determined. The adsorption effect of dust suspended in the atmosphere was detected in the area. A number of primary 
and secondary pollutants all resulting from refining, petrochemical and cottage facilities were monitored. Concentration roses of a number of airborne chemicals were executed in order to determine the dominate sources surrounding the urban estate. Rules and regulation of KUEPA must be strictly applied and regular check ups are mandatory at this stage.

\section{References}

[1] Pelliccioni, A. and Tirabassi, T., Air dispersion model and neural network: A new perspective for integrated models in the simulation of complex situations, Environmental Modeling \& Software 21, 539-546, 2006

[2] Al-Salem, Sultan M. and Al-Haddad, Amir A., Pollutants Monitoring and Source Determining: Effect of Oil Refineries on a Residential Area, Proceedings of the $2^{\text {nd }}$ International Conference on Scientific Computing to Computational Engineering ( ${ }^{\text {nd }}$ IC-SCCE), Set No: 960-530-080-X, Athens, Greece, July, 2006

[3] El-Fadel, M., Zeinatit, M., Ghaddar, N. and Mezher, T., Uncertainty in estimating and mitigating industrial related GHC emissions, Energy policy, vol: 29, pp1031, 1999

[4] Al-Salem, S.M. and Bouhamrah, W.S., Ambient Concentrations of Benzene and Other VOCs At Typical Industrial Sites in Kuwait and Their Cancer Risk Assessment, Research Journal of Chemistry and Environment, Vol.: 10(3), Pp: 42-46, 2006

[5] Klemp, D., The Augsburg emission evaluation experiment, Atmo. Env. Supplement I, 1-120, 2002

[6] Al-Salem, Sultan M., and Khan, Abdul Rehamn; Methane Dispersion Modeling and Source Determination around Urban Areas in Kuwait, Proceedings of the $1^{\text {st }}$ International Conference and Exhibition on Green Industry, Bahrain, November, 2006

[7] Kuwait Al-YOUM Appendix 533, KUEPA regulations, law 210/2001

[8] Wark, Kenneth, Warner, Cecil F., and Davis, Wayne T., Air pollution: its origin and control, $3^{\text {rd }}$ edition, published by Wesley \& Edison, 1998

[9] Al-Bassam, E. and Khan, A., Air pollution and road traffic in Kuwait, Proceedings of Urban Transport X conference, Urban Transport and the Environment in the 21st Century, Edited by C. A. Brebbia and L. C. Wadha, WIT Press, Ashurst Lodge, Southampton SO40 7AA, UK, 19-24 ${ }^{\text {th }}$, Dresden, Germany, Pp 741-750, May 2004

[10] Al-Hajraf. S; D. Al-Ajmi; A. Khan; H. Tang; A. Wahner; D. Klemp. 2005. Air Quality Assessment of Ali Sabah Al-Salem Urban Community, KISR Report EC031C

[11] Pasanen, Pertti, Hyttinen, Marko, Kalliokoski, Pentti, Adsorption, Desorption and Chemical Reactions in the Particulate Matter Collected on Air Filters and Ducts, Research project SYTTY, Finish Research Program on Environmental Health, 2004 